\title{
Barrancabermeja: tras las huellas de la memoria de la Organización Femenina Popular*
}

Revista Colombiana de Educación, N. 62. Primer semestre de 2012, Bogotá, Colombia.
//Barrancabermeja: following the

memory footsteps of the Popular

Female Organization

//Barrancabermeja: seguindo

os passos da memória da

Organização Feminina Popular

María Carolina Alfonso Gil**

Este artículo hace parte de los resultados de la tesis de maestría titulada Las políticas de la memoria y la identidad política en las mujeres de la Organización Femenina Popular, de la línea de investigación Memoria, Identidad y Sujetos Sociales correspondiente a la Maestría en Estudios Sociales de la Universidad Pedagógica Nacional.

Licenciada en Educación Básica con Énfasis en Ciencias Sociales y magister en Estudios Sociales de la Universidad Pedagógica Nacional. Docente-investigadora del Departamento de Ciencias Sociales de la Universidad Pedagógica Nacional, vinculada a los grupos de investigación Sujetos y nuevas narrativas en investigación y enseñanza de las ciencias sociales, en la línea Memorias, identidades y actores sociales de la Universidad Pedagógica Nacional y Cyberia de la Universidad Distrital Francisco José de Caldas. Correo electrónico: didasco2@gmail.com

\section{Resumen}

Las mujeres han jugado un papel político fundamental en los procesos de reconstrucción de la memoria, pues en las comunidades ellas resignifican los recuerdos, los territorios, las fechas conmemorativas, ya sea a favor de quienes impulsaron prácticas de opresión y silenciamiento o de quienes fueron o son objeto de dichas prácticas. Es en este último escenario donde se encuentran las mujeres de la Organización Femenina Popular de la ciudad de Barrancabermeja, en el Magdalena Medio. Esta organización fundada en 1972 tiene un proceso político caracterizado por la disputa con el Estado y diferentes actores armados, la maternidad como bandera política, referida a la reivindicación de la mujer madre como defensora de la vida y en contra de la guerra, y la defensa de los derechos humanos. Son estas líneas bajo las cuales se analizan las políticas de la memoria de la organización, en tres niveles propuestos por Elizabeth Jelin: el político y cultural, donde se ubican "las memorias como objeto de disputas, conflictos y luchas; el simbólico y personal, donde se analizan "las memorias como procesos subjetivos, anclados en experiencias y en marcas simbólicas y materiales"; y el histórico y social, que estudia las transformaciones de la memoria en distintas sociedades y "espacios de luchas políticas e ideológicas (2002, p.2)".

\section{Palabras Clave}

Políticas de la memoria, mujer, conmemoración, marca territorial, significación. 


\begin{abstract}
Women have played a very important political role in the memory reconstruction process since they redefine memories, territories and special dates of communities whether supporting people who foster oppression and silence or those people ruled now and then by such practices. In the latter scenario we could find women of the Popular Female Organization from Barrancabermeja City, Middle Magdalena, an organization which was founded in 1972 with a political process characterized by a dispute between the state and several armed players, the motherhood as a political symbol claiming the woman as mother and life-and-Human Rights protector against war. Under these items, politics of the organization memories are analyzed and based on three levels proposed by Elizabeth Jelin: political and cultural level, i.e. "memories as object of disputes, conflicts and fights"; symbolic and personal level, i.e. "memories as subjective processes linked to experiences and material-and-symbolic footprints"; and historical and social level, which studies memory changes of different societies and "rooms for political and ideological fights" (2002, p. 2).
\end{abstract}

\title{
Keywords
}

Statecraft of memory, woman, celebration, territorial sign, meaning.

\section{Resumo}

As mulheres tem desempenhado um papel político fundamental nos processo de reconstrução da memória, pois, nas comunidades, elas ressignificam as recordações, os territórios, as datas comemorativas, seja a favor dos que impulsionaram práticas de opressão e silenciamento, seja a favor dos que foram ou são objeto dessas práticas. É nesse último cenário que se encontram as mulheres da Organização Feminina Popular da cidade de Barrancabermeja, no Médio Magdalena. Esta organização, fundada em 1972, tem um processo político caracterizado pela disputa com o Estado e com diferentes atores armados; pela maternidade como bandeira política, referida à reivindicação da mulher mãe como defensora da vida e contra a guerra; e pela defesa dos direitos humanos. É sob essas linhas que se analisam as políticas da memória da organização, em três níveis propostos por Elizabeth Jelin: o político e cultural, onde se localizam "as memórias como objeto de disputas, conflitos e lutas"; o simbólico e pessoal, onde se analisam "as memórias como processos subjetivos, ancorados em experiências e em marcas simbólicas e materiais"; e o histórico e social, que estuda as transformações da memória em distintas sociedades e "espaços de lutas políticas e ideológicas" (2002, p.2)

\section{Palavras chave}

Políticas da memória, mulher, comemoração, marca territorial, significação. 


\section{Presentación}

La memoria tiene un carácter fundacional que está relacionado con un ejercicio político, ya que pone en evidencia los discursos marginales, las disputas por el saber, los lugares de legitimación de las instituciones y los sujetos. Este campo en disputa, que configura la memoria, es analizado en el caso de la Organización Femenina Popular (OFP), en tres niveles propuestos por Elizabeth Jelin (2002): el nivel político y cultural, el simbólico y personal y el histórico social. Estos tres niveles se expresan en prácticas sociales sistemáticas de producción de memoria, que articulan la identidad de colectivos y organizaciones como la OFP. Según Aguilar (2008), estas prácticas se constituyen en políticas de la memoria, entendidas como "todas aquellas iniciativas de carácter público (no necesariamente político) destinadas a difundir o consolidar una determinada interpretación de algún acontecimiento del pasado de gran relevancia para determinados grupos sociales y políticos, o para el conjunto de un país" (p. 53).

El nivel político se evidencia en la formulación de las políticas de la memoria de la OFP y su disputa con el Estado y con los cuerpos armados paraestatales que han vulnerado sus derechos. En las fechas conmemorativas, en sus espacios y en las movilizaciones, la OFP expresa su versión sobre el pasado reciente y lo confronta con la construcción que sobre dicho pasado ha legitimado el Estado.

En el nivel simbólico se encuentran los lemas de la Organización y los símbolos construidos durante su vida organizativa: la olla, las llaves, las flores amarillas, las cintas de colores, las batas negras, la bandera contra la guerra. En cuanto al nivel histórico, este se analizó de manera transversal a los dos anteriores, en tanto en ellos se expresa la manera como se ha transformado la memoria de la OFP.

De esta forma, el presente artículo aborda dos casos específicos -las marcas territoriales y la producción iconográfica-, en las políticas de la memoria de la OFP. En el nivel político se analizan las marcas territoriales de la organización representada en la Casa de la mujer y la conmemoración del 20 de Julio, y el nivel simbólico el análisis de una de sus producciones iconográficas referida a la conmemoración mencionada anteriormente.

\section{Marcas territoriales y conmemoraciones en la OFP}

La OFP a lo largo de su vida organizativa ha apropiado una serie de fechas conmemorativas y espacios de vida como referentes políticos de su propuesta social. Estos planteamientos son los que se abordan desde las marcas territoriales de la memoria y las conmemoraciones de 
fechas significativas para la Organización y sus manifestaciones y movilizaciones.

En las marcas territoriales se analizó la Casa de la Mujer como vehículo de la memoria (Jelin, 2002) en tres momentos: primero, sus características generales y funciones en relación con las políticas de la Organización; segundo, las condiciones de origen de la Casa, su fundación; en tercer lugar, la incursión del paramilitarismo y su incidencia en las políticas de la Organización y de esta manera, en la función de la Casa de la mujer que se convirtió, ante la ausencia del Estado, en refugio de las familias amenazadas por estos grupos.

Las fechas significativas, para la Organización y sus manifestaciones y movilizaciones, se abordaron en dos momentos: en el primero, las conmemoraciones y en el segundo, la producción iconográfica de la Organización. En el primer momento, se analizaron dos fechas: el 20 de Julio, como día de la fundación de la Organización; y el 25 de noviembre, Día Internacional de la No Violencia contra la Mujer.

- La Casa de la Mujer y su devenir como marca de la memoria

La memoria tiene en los espacios físicos un referente de sentido creado por los hombres y mujeres que los habitan; las experiencias y los recuerdos están anclados a situaciones y lugares que son significativos para los individuos y los colectivos. De este modo, un espacio se configura en lugar de memoria en el momento en que los colectivos le otorgan centralidad en sus luchas políticas. Tal como lo plantea Jelin (2003): "Lo que intentamos comprender no es solamente la multiplicidad de sentidos que diversos actores otorgan a espacios físicos en función de sus memorias, sino los procesos sociales y políticos a través de los cuales estos actores (o sus antecesores) inscribieron los sentidos en esos espacios -o sea, los procesos que llevan a que un "espacio" se convierta en un lugar" (p. 3).

Estos lugares adquieren el carácter de vehículos de memoria desde dos perspectivas: de un lado, en tanto los emprendedores de la memoria (Jelin, 2002) agencian prácticas y reivindicaciones políticas en dichos espacios, y los convierten en referentes de una comunidad y sus luchas políticas. De otro lado, "Estos espacios se convierten en lugares de luchas entre quienes intentan transformar su uso y de esa manera (o para) borrar las 
marcas identificatorias que revelan ese pasado, y otros actores sociales que promueven iniciativas para establecer inscripciones o marcas que los conviertan en "vehículos" de memorias, en lugares cargados de sentidos" (Jelin, 2003, p. 11).

Los espacios físicos de la OFP, como marcas territoriales en las cuales la memoria cobra un lugar político, se han constituido en relación con dos elementos: el primero, el carácter femenino de la Organización y el segundo, la relación de la OFP con el Estado. La Casa de la Mujer es una marca territorial de la memoria, ya que ella, además de ser la sede de su trabajo, es un referente simbólico y subjetivo de las mujeres que han disputado este espacio con los actores armados y el Estado, tal como se presenta a continuación.

- La Fundación, el comienzo de un camino de vida organizativa

En 1972 se crearon los clubes de amas de casa como iniciativa de la pastoral social de la Iglesia de Barrancabermeja. En estos se ofrecían a las mujeres cursos de capacitación, a la vez que se adelantaba la evangelización. Para el año 1976, la OFP asumió un carácter laico, sin abandonar su cercana relación con la pastoral de la Iglesia Católica. En sus primeros años, la Casa fue un lugar con dos características: centro de capacitación en actividades manuales (costura y cerámica) y lugar de encuentro para discutir las problemáticas propias de las mujeres madres, esposas, hijas, compañeras (seguridad alimentaria y maltrato intrafamiliar). La primera característica, referida a las actividades manuales, fue la estrategia de trabajo de la Casa para vincular a las mujeres a la Organización. Los talleres de manualidades como un espacio de encuentro para la capacitación artesanal fueron y continúan siendo espacios de formación en derechos humanos y salud.

Los talleres de manualidades están orientados a ofrecer a las mujeres la posibilidad de contribuir con la economía familiar y las acerca a las apuestas políticas de la Organización, que son conocimiento y exigibilidad de los derechos, oposición a la guerra y reivindicación de la condición de la mujer. Al respecto Jackeline, mujer que hace parte de la mesa directiva de la Organización (2009), plantea:

Los programas de la OFP no son el fin, son el medio para organizar a la mujer, son el pretexto que nos inventamos, y les decimos a las mujeres que aquí hay esto para que salgan de esas cuatro paredes de la casa y sepan que hay espacios más amplios en los que ella puede participar y empezar a hacer camino en la comunidad y que no está sola, que cuenta con otras mujeres (...) para que se prepare para 
la exigibilidad de sus derechos, que ella está yendo a la charla de psicología y se le está haciendo todo un trabajo psicosocial a ella y sus hijos, para que ella recupere su condición, para que ella vaya al servicio de salud y exija el derecho a la salud que tiene, porque el Estado debe garantizar eso.

La Casa de la Mujer de la OFP se origina como un proceso de la Iglesia Católica, obedeciendo a su labor evangelizadora, y termina consolidándose como un proyecto laico de mujeres que denuncian la falta de garantías para el acceso a los derechos básicos (salud, educación y seguridad alimentaria) por parte del Estado.

- La Casa de la Mujer durante la incursión del paramilitarismo El segundo momento de constitución, o de una nueva capa de sentido como lo denomina Jelin (2002), es al comienzo del año 1998, cuando empezó en Barrancabermeja la incursión de grupos paramilitares en los barrios de la ciudad, que tenía como objetivo militar y político expulsar lo que los paramilitares Ilamaron las milicias urbanas de la guerrilla. La investigación respecto a la incursión del paramilitarismo en la región del Magdalena Medio, adelantada por SINALTRAINAL, (Sindicato Nacional de Trabajadores de la Industria de Alimentos) en el año 2002, permite analizar el panorama general de este proceso auspiciado por el Estado. En este estudio, Libardo Sarmiento describe el modelo Magdalena Medio y distingue tres fases en su consolidación y expansión:

De acuerdo con las declaraciones de uno de los voceros más representativos del paramilitarismo en Colombia, Carlos Castaño, en la primera fase del modelo paramilitar [...] se trata de «liberar» mediante la guerra amplias zonas de la subversión y de sus bases populares de apoyo, imponiendo el proceso de concentración de la tierra, la modernización vial, de servicios y de infraestructura, el desarrollo del capitalismo ganadero y la nueva estructura jerárquica y autoritaria en la organización social y política de la región. En la segunda fase del modelo se trata de «llevar riqueza a la región» a través de la entrega subsidiada de tierras, de la generación de empleo, la concentración de la población en centros poblados, la construcción de puestos de salud y de escuelas, del 
regalo de energía eléctrica, de construcción de represas para el suministro de agua y de vías de comunicación, de la adecuación de tierras, la asistencia técnica y el préstamo de dinero para la producción. Esta segunda fase lleva a la tercera fase del modelo que está en su consolidación y legitimación. Una vez se consolide el modelo de «seguridad» en las regiones «liberadas», sin subversivos ni bases comunitarias de apoyo, los paramilitares consideran que dejarán de ser una «rueda suelta para el Estado». (p. 6)

Tomando como pretexto este modelo se incrementaron las desapariciones, los asesinatos, las amenazas y el desplazamiento de familias completas. En 1998 se presenta la incursión armada del paramilitarismo en la ciudad, "la masacre del 16 de mayo que se da en la zona suroriente en los barrios El Campín, Nueve de Abril y María Eugenia. Allí fueron asesinadas siete personas, fueron desaparecidas $25^{\prime \prime}$ (p. 9). También registra- SINALTRAINAL- como fueron asesinadas 8 personas el 28 de febrero de 1999, cuando "tres camionetas ocupadas por unos 30 paramilitares hicieron un recorrido de muerte por los alrededores de Barrancabermeja" (SINALTRAINAL, p. 10-12).
La Organización registra en su periódico Mujer Popular estos hechos:

El 27 de enero de 2001 a las once de la mañana, 2 paramilitares llegan a la Casa de la Mujer en el sector suroriental, en el barrio El Campestre, comuna 7 de Barrancabermeja, exigiendo las Ilaves y la desocupación de la casa antes de las tres de la tarde para convertirla en centro de operaciones paramilitares. La respuesta, sin vacilaciones, de la Organización Femenina Popular, rompió la lógica de los paramilitares que venían expropiando las viviendas. (...) Según el relato de Gloria Suárez, Ese mismo día hacia las cinco de la tarde, en lugar de desocupar la casa en el plazo fijado, había 118 personas albergadas en ella, más de 20 familias, todas del sector, a quienes también les habían exigido salir de sus casas y de Barrancabermeja entre tres y doce horas.

La mayoría eran familias desplazadas, acusadas por los paramilitares de ser auxiliadores o familiares de la guerrilla. Como algunas mujeres amenazadas participan en el 
proceso organizativo de OFP, recurrieron a la Casa de la Mujer con sus trasteos, con su cama, con su ropa y con los niños. Así la sede se convirtió en un albergue humanitario, y con el acompañamiento de organizaciones sociales del país y de la comunidad internacional realizamos vigilias de resistencia día y noche durante tres meses consecutivos. (Periódico, 2006, p. 16)

La Casa de la Mujer durante este periodo fue el refugio de decenas de familias, lo que la convirtió en objetivo de la acción paramilitar. Ante esta situación de hostigamiento permanente, la OFP adelantó una serie de acciones políticas entre las que se encontraban: las vigilias, las marchas de la luz y la reivindicación como organización defensora de derechos humanos y en oposición a la guerra. Es así como las mujeres la consideran:

Un símbolo de resistencia, de denuncia, de defensa del territorio, de dignidad. Las casas de la Organización Femenina Popular son un escenario donde fluye la vida, con movimiento propio y opinión y siempre han sido un símbolo y referente para las comunidades. Sin embargo, este símbolo cobra una mayor dimensión de resistencia desde la noche del 11 de noviembre de 2001, cuando un grupo de cerca de 20 hombres derribaron la sede ubicada en el sector norte de Barrancabermeja, en el barrio La Paz. Se llevaron hasta la última piedra. Era el cumplimiento de la amenaza que un mes antes el paramilitar alias "El Gato" hiciera a dos mujeres de la Organización Femenina Popular, anunciando un hecho que según él causaría sorpresa y dolor. La respuesta de la OFP ante esta agresión fue la creación de una campaña nacional e internacional Ilamada Marcha del ladrillo, realizada con aportes en dinero o en material de construcción. Entre mujeres y hombres y organizaciones sociales se logró la reconstrucción de la casa, con más dolientes, más fuerte, más grande...Un año después el proceso organizativo también estuvo más fortalecido. (Periódico, 2006, p. 16)

Durante la conmemoración del 20 de Julio de 2002 se reinauguró la casa del sector norte, en la comuna 5 de Barrancabermeja. "Esta casa de la mujer del sector norte, no es una casa más de la Organización Femenina Popular, desde ahora 
y para siempre será el templo de la solidaridad en Barrancabermeja" (Periódico, 2002, p.8).

La casa como marca territorial de la memoria es la vivienda donde se resguarda y protege, donde las huellas emocionales y simbólicas están presentes, donde la subjetividad encuentra parte de sus rastros materiales. Es el lugar de la mujer como madre, como esposa, como líder. La casa como espacio privado adopta un nuevo significado como lugar de reivindicación y resistencia política.

- El 20 de Julio como una conmemoración por la autonomía de las mujeres.

Conmemorar es un ejercicio político que ubica un hecho desde el presente, no es el pasado como marca de un hecho inmutable, sino como lugar político de enunciación del presente. De esta forma las conmemoraciones están sujetas a cambios. El sentido de las fechas, como lo plantea Jelin (2001), "cambia a lo largo del tiempo": las nuevas generaciones, acciones sociales y condiciones políticas les otorgan nuevos sentidos, objetivos y lecturas. "Estos momentos son hitos o marcas, ocasiones cuando las claves de lo que está ocurriendo en la subjetividad y en el plano simbólico se tornan más visibles, cuando las memorias de diferentes actores sociales se actualizan y se vuelven "presente" (Jelin, 2001, p. 103).

El 20 de Julio es celebrado dentro de la historia de la Organización Femenina Popular "como la fecha desde la cual partió el proceso organizativo, fecha que coincide con la celebración de la independencia nacional. En este día se reitera el proceso independiente y decidido a favor de la mujer, un proceso civilista en contra de la guerra, que año a año le aporta a Colombia elementos de paz y de vida. Según Yolanda Becerra, directora de la OFP, "Esta fecha es asumida simbólicamente como aniversario de la OFP, en honor a la autonomía de un movimiento social transformador, que impulsado por las mujeres, como sujetas políticas, logre independencia y libertad" (Periódico, 2005, p.12).

Se legitima un hecho fundacional por su carácter histórico y por su significado social, es decir, se considera la civilidad como lugar legítimo que retoma estos ideales. El 20 de Julio es el hito fundacional de la OFP por su construcción política como referente de la Organización. Al respecto manifiesta Yolanda Becerra (2010):

Originalmente no tenemos la fecha, el año si, pero el día no, no lo encontramos en las actas de la Organización Femenina Popular. Y creemos que el 20 de Julio es una fecha muy importante, porque habla de la independencia y las autonomías. No porque el 20 de Julio se hubiera resuelto el problema de las autonomías del país, sino por- 
que queríamos reivindicar el sentido de las autonomías. Entender que ser autónomo, construir independencia y autonomías comienza por uno mismo. Es apropiarse de la fecha con otro sentido.

Es apropiarse del ejercicio que realizan los emprendedores de la memoria. Darle otro sentido, en este caso, a la autonomía como proceso que empieza en el sujeto. Un tipo de sujeto, mujer, que está llamada a asumir su libertad, a ser autónoma desde su propia condición, y un tipo de conmemoración que está basada en la libertad y la autonomía que deben ser constantemente configuradas. Como estrategia, la Organización hace talleres cuyo tema es la conmemoración del 20 de Julio. Para el caso del año 2002, en el aniversario 32, el taller contemplaba 9 momentos que denominan como una novena, en la que cada día se adelantaba una actividad diferente que les permitió "conocer, profundizar y encontrarle el gusto a este proceso" (OFP, Cartilla, 2002).

En la novena se reiteran diariamente 6 pasos: entonar el himno de la OFP, realizar la dinámica, hacer la reflexión, plantear los compromisos, realizar el exorcismo de la vida, la sabiduría y la resistencia, y terminar el día con la Oración por la civilidad. Hacer una novena con motivo del 32 aniversario de la OFP está relacionado con prácticas religiosas tradicionales que han tomado un carácter político, no solo por el origen de la Organización, fundada por la pastoral social de la Iglesia Católica de Barrancabermeja, sino por el acompañamiento que esta ha hecho al movimiento social de esta ciudad, sobre todo en los años 70 y 80 bajo la influencia de la Teología de la liberación.

La novena, al igual que las vigilias o marchas de la luz, juega un papel político en dos sentidos. Primero, convoca a la movilización y tiene el respaldo de la Iglesia y segundo, es estrategia de visibilización de las prácticas de los grupos armados: desapariciones, amenazas, desplazamiento, asesinatos. Al igual que en el caso de Neuquén en Argentina, donde los rituales religiosos fueron asimilados con reivindicaciones políticas, la OFP se moviliza. En la ciudad de Neuquén: "Durante la última dictadura militar (1976-1983), la iglesia operó como lugar de refugio y resistencia para la población neuquina que se oponía el régimen, amparada por la figura de Don Jaime de Nevares, obispo de Neuquén (...) La iglesia abrió en el seno mismo de sus rituales religiosos habituales, como las misas y las procesiones, un espacio 
para que los afectados por el terrorismo de Estado hicieron públicas sus denuncias y reclamos" (Mombello, 2003, p.154). De esta misma forma las marchas, las vigilias y las novenas se configuran como espacios de denuncia de la OFP.

Con la novena, la OFP busca cimentar las bases de la Organización, consolidar el lugar de sus miembros y su legitimidad política. De allí la importancia del trabajo colectivo que se hace presente en cada día de la novena con elementos como: "Cuando encontramos espacios propios de mujeres para conversar, visibilizar lo que nos duele, soñamos, le encontramos salida a las situaciones por difíciles que sean" (OFP, 2002 , p. 6). "Las mujeres juntas han abierto caminos que se consideraban cerrados por siempre para ellas (...) Exigir derechos necesita valor civil y esto da frutos si nos juntamos $y$ tenemos claro lo que queremos $y$ ese querer se convierte en un querer colectivo" (Cartilla, 2002, p.8).

Hacer parte de una organización con un recorrido de más de 32 años requiere que sus integrantes conozcan sus logros, acciones, posibilidades. Este tipo de talleres está orientado no tanto a los miembros "más antiguos", sino a los de más reciente vinculación, en una práctica de aprendizaje y socialización de las memorias. Se hace necesario que los integrantes de la Organización tengan presente la historia cronológica, las vivencias y acciones políticas de sus miembros durante los periodos de crisis. El factor subjetivo en el desarrollo de estas actividades es básico, de allí que se acuda a historias de vida para recrear los hechos.

Las nuevas generaciones pueden llegar al escenario público con otras visiones, basadas en aprendizajes de parte de la experiencia pasada (decir no a la lucha armada, por ejemplo), pero al mismo tiempo reavivar las memorias, interrogando a los mayores acerca de sus compromisos $y$ sus vivencias en ese pasado conflictivo y represivo (...) La transmisión del pasado y su sentido es objeto de luchas abiertas y de estrategias de políticas de la memoria que se despliega en tres vías simultáneas: la inercia social de los procesos de transmisión de tradiciones y saberes sociales acumulados, la acción estratégica de "emprendedores de la memoria que desarrollan políticas activas de construcción de sentidos del pasado, $y$ los procesos de transmisión entre generaciones" (Jelin, 2002, p.125)

De esta forma, las líderes de la OFP son las emprendedoras de la memoria quienes, mediante conmemoraciones, 
talleres de formación y acciones de denuncia, reivindican su lugar como organización femenina. El 20 de Julio para este caso es una nueva construcción de sentido del pasado que requiere ser escenificada.

- El 20 de Julio como producción iconográfica.

Esta nueva construcción de sentido, en términos de Roland Barthes (2006), se refiere a una mitificación del mito, es decir, a una politización del habla, que está presente en la producción iconográfica de la organización y en sus procesos de significación. La producción iconográfica que hace parte de estas fechas, manifestaciones y espacios, fue abordada desde el análisis semiológico del mito (Barthes, 2006), que es "Un habla (...) No podría ser un objeto, un concepto o una idea; se trata de un modo de significación, de una forma (...) El mito no se define por el objeto de su mensaje, sino por la forma en que se lo profiere: sus límites son formales, no sustanciales" (p. 199). El objeto es un referente del mito, lo que le permite ser enunciado. Lo que hace el mito es deformar el objeto, no invisibilizarlo; el mito despolitiza el habla en tanto la sustrae a su contexto de configuración. De esta forma el mito fundacional de la organización, ubicado el 20 de Julio, es a su vez un mito robado, que de una conmemoración nacional naturalizada bajo la idea de libertad, es resignificado y apropiado por la organización de otra manera y con otro objetivo político. La referencia al mito de esta conmemoración se aborda desde el siguiente volante:

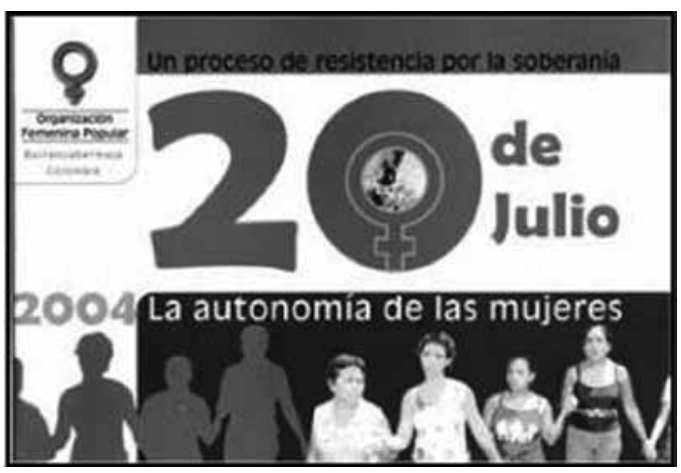

Ilustración 1. Conmemoración 20 de Julio. Autonomía de las mujeres. Barrancabermeja. Volante. OFP. 2004. 
La imagen está compuesta por tres elementos. Primero, el enunciado "Un proceso de resistencia por la soberanía. 20 de Julio, 2004. La autonomía de las mujeres". El segundo elemento, la imagen de la cadena de mujeres en la parte inferior del texto. Finalmente, el signo que simboliza a la mujer, tanto en el encabezado de la Organización, como en el número 20. La conmemoración del 20 de Julio como fecha de fundación de la OFP, se reivindica para exaltar un proceso de construcción de soberanía, de autonomía de las mujeres, de las mujeres como colectivo, de las mujeres que trabajan juntas, que caminan juntas.

La cadena está relacionada a su vez con el color lila (OFP, 2006). Este simboliza la no violencia y es el cuerpo de la mujer el que defienden como colectivo. El 20 de Julio es de las mujeres, de su proceso organizativo, de su lucha contra la violencia, contra la militarización, por la defensa de su autonomía. La conmemoración del 20 de Julio es, en términos de Barthes (2007), una palabra robada, un mito robado que es mitificado. Es decir, como fecha institucional el 20 de Julio, grito de independencia, cuenta con un significado histórico nacional; este es un significante vacío, 20 de JulioIndependencia, la fecha es un símbolo referido a un hecho histórico institucionalizado como fiesta patria. La OFP toma esta fecha y le da un nuevo significado, relacionado con las luchas de las mujeres por la autonomía y la soberanía como proyecto colectivo que tiene en los cuerpos femeninos uno de sus referentes. Esta conmemoración es un signo en disputa, -para Barthes (2006) un signo es la unión entre el significante (la imagen) y el significado (la definición) del término- que la organización pone en cuestión, al desnaturalizar el habla referida a la resistencia, la soberanía y la independencia. La OFP tomó este lenguaje para sí y lo vuelve contra su significante anterior. Transforma esta fecha en un habla, en un mito otro, en un mito robado. Que ahora es el mito fundacional de la OFP.

\section{Conclusiones}

Las políticas de la memoria de la Organización Femenina Popular se han constituido en parte fundante del trabajo organizativo que ha atravesado por diferentes etapas, desde su fundación por parte de la Iglesia Católica, hasta su consolidación como defensora de derechos humanos frente a la expansión y consolidación del paramilitarismo en la región.

La disputa por los espacios, las significaciones y la lucha por la permanencia en el territorio, está atravesada por la condición mujeres contra la guerra y a favor de un proyecto de paz en el que la memoria y la justicia están ligadas al ejercicio de la exigibilidad de los derechos, a la apropiación de los espacios públicos y la politización de los espacios considerados como privados, uno de ellos la Casa de la mujer. 
La resignificación de la conmemoración del 20 de Julio, como mito fundacional de la Organización, es muestra del ejercicio político de agenciamiento de las políticas de autonomía y exigibilidad de los derechos que hace la Organización frente al Estado y la sociedad en general, tomando un significado de libertad y autonomía naturalizado para ubicarlo en un contexto donde los efectos del conflicto armado hacen de este tipo de organizaciones blanco de la persecución de los grupos armados y señalamientos por parte del Estado.

\section{Referencias}

Aguilar, P. (2008). Políticas de la memoria y memorias de la política. Madrid: Alianza.

Alfonso, C. (2010). Entrevista a Yolanda Becerra, líder de la OFP. Bogotá.

Alfonso, C. (2009). Entrevista a Jackeline Rojas, líder de la OFP. Barrancabermeja.

Barthes, R.(2006). Mitologías. Mexico: Siglo XXI.

Jelin, E. (2001). Exclusión, memorias y luchas políticas. En: M. D., Cultura y transformaciones sociales en tiempos de globalización (91-107). Buenos Aires: CLACSO.

Jelin, E. y Langland, V. (2003). Monumentos, memoriales y marcas territoriales. En J. E. V., Monumentos, memoriales y marcas territoriales. (págs. 5-19). Madrid: Siglo XXI.

Jelin, E. (2002). Los trabajos de la memoria. Madrid: Siglo XXI.

Jelin, E. OFP. (2002). Nuestra casa será el templo de la solidaridad. Periódico Mujer popular, pág. 9.

Jelin, E. OFP. (2005). 33 años de resistencia. Cronología de un proceso de logros. Periódico Mujer popular, pág. 12.

Jelin, E. OFP. (2006). Cartilla: Sujetas politicas para la vida. Historia. Barrancabermeja, Colombia.

Jelin, E. Sinaltrainal. (2002). http://www.sinaltrainal.or/anterior/ Textos/parasmada2004.pdf. Recuperado el 2 de Septiembre de 2010. 